\title{
THE 1990 CAPL OPERATING PROCEDURE: AN OVERVIEW OF THE REVISIONS
}

\author{
JAMES A. MACLEAN
}

In this article, the author compares the 1981 and 1990 CAPL Operating Procedures, emphasizing the revisions which have been made and both the legal and business reasons for those changes.

\section{TABLE OF CONTENTS}

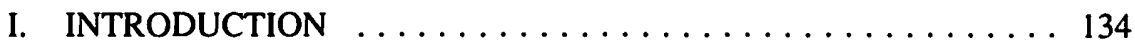

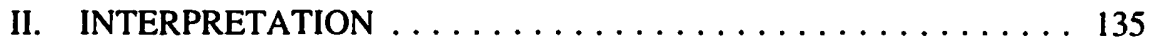

III. APPOINTMENT AND DUTIES OF THE OPERATOR $\ldots \ldots \ldots 141$

A. ROLE OF THE OPERATOR ............... 141

B. THE APPOINTMENT AND REPLACEMENT

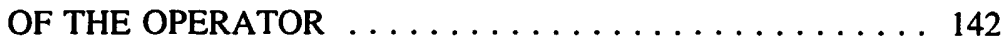

C. DUTIES OF THE OPERATOR $\ldots \ldots \ldots \ldots \ldots \ldots \ldots 145$

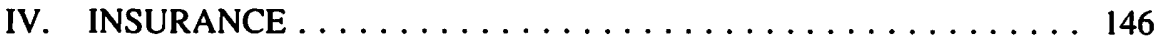

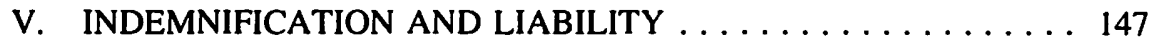

VI. FINANCIAL PROVISIONS $\ldots \ldots \ldots \ldots \ldots \ldots \ldots \ldots \ldots 149$

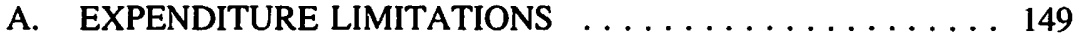

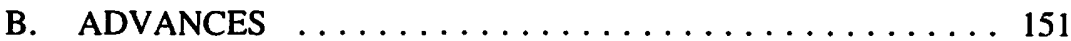

C. DEFAULT AND REMEDIES $\ldots \ldots \ldots \ldots \ldots \ldots \ldots \ldots 152$

D. COMMINGLING OF FUNDS $\ldots \ldots \ldots \ldots \ldots \ldots \ldots 154$

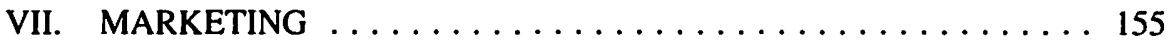

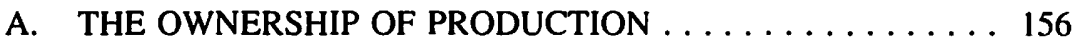

B. THE DISPOSITION OF PRODUCTION WHERE A PARTY DOES NOT TAKE IN KIND . . . . . . . . 156

C. THE MARKETING FEE . . . . . . . . . . . . 159

D. THE MISCELLANEOUS MARKETING PROVISIONS $\ldots \ldots 160$

VIII. INDEPENDENT OPERATIONS $\ldots \ldots \ldots \ldots \ldots \ldots \ldots \ldots \ldots$

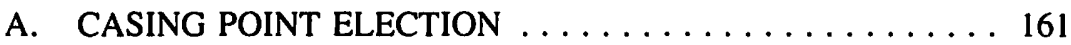

B. THE MECHANICS OF CONDUCTING AN ARTICLE X INDEPENDENT OPERATION $\ldots \ldots \ldots \ldots \ldots \ldots \ldots 162$

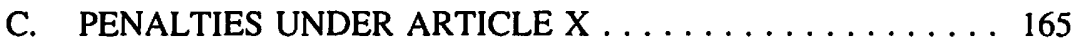

D. THE GENERAL PROVISIONS OF ARTICLE X $\ldots \ldots \ldots 171$

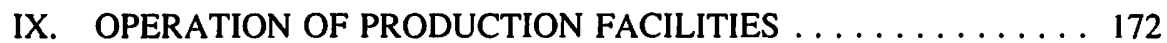

X. DISPOSITION OF INTERESTS $\ldots \ldots \ldots \ldots \ldots \ldots \ldots \ldots 172$

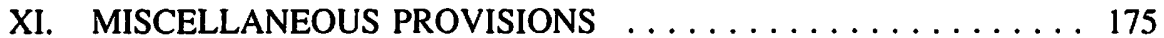

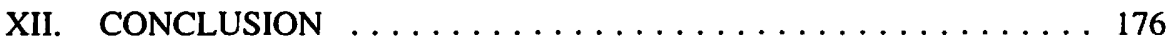

Senior Land Representative, Chevron Canada Resources, Calgary, Alberta and member of the committee of the Canadian Association of Petroleum Landmen responsible for the preparation of the 1990 CAPL Operating Procedure. The author wishes to express his gratitude to Mr. James E. $\mathrm{O}^{\prime}$ Byme, President of $\mathrm{O}^{\prime}$ Byme Resource Management Ltd. and Chairman of the CAPL Operating Procedure Committee, for his guidance with respect to the subject matter and to Mr. J. Jay Park, Partner, Macleod Dixon, for his assistance in editing this article. 


\section{INTRODUCTION}

The oil and gas industry of the late 1980s was very different from that which existed at the beginning of the decade. The dream of $\$ 80$ a barrel oil by 1990 had vanished. It was cruelly replaced by a prolonged period of low commodity prices, something which was particularly ironic, given that the oil and gas industry had finally been successful in obtaining deregulation of oil and gas prices. The promise of ready access to natural gas markets had also teased the oil and gas industry throughout the decade, as industry players waited for the inevitable explosion of the "natural gas bubble" - always just two years away, such that there was a huge surplus of readily available natural gas. Was it any wonder that there were a large number of financially distressed oil and gas exploration companies, and that their condition affected the various joint venture arrangements under which they held oil and gas properties with other industry players?

It was in the context of these difficult conditions that the Canadian Association of Petroleum Landmen, in consultation with interested parties, revised the 1981 CAPL Operating Procedure.'

The CAPL committee responsible for the preparation of the 1990 CAPL Operating Procedure had a number of objectives, the principal ones being:

- to balance the needs of operators with those of non-operators;

- $\quad$ to balance the needs of an individual owner with those of the owners as a whole;

- $\quad$ o address specific problem areas where it was generally perceived that the 1981 form was deficient;

- to review the suitability of traditionally accepted provisions for contemporary operations;

- to minimize the degree to which foreseeable, easily avoidable problems frustrate operations;

- to have a sound basis in law and to express clearly the respective rights and obligations of the parties;

- to be "comfortable" in the street;

- to edit the document, so that the drafting style would be consistent; and

- to assist all users in better understanding the philosophy and principles of the document through the inclusion of detailed annotations. ${ }^{2}$

The review which follows is designed to provide the user with an overview of the material changes which have been made to the 1981 form in the context of those objectives. That being the case, the complexities and subtleties associated with the 1990

I. The 1990 CAPL Operating Procedure is the fifth version of the standard form operating procedure prepared by the Canadian Association of Petroleum Landmen to address the relationship of two or more parties holding joint interests in lands. Previous versions of the form were the seldom used 1969 and 1971 CAPL Operating Procedures and the generally accepted 1974 and 1981 Operating Procedures. For simplicity, the standard form CAPL Operating Procedures have been referred to in the text by year, such as "the 1990 document" or the "1981 form."

2. James E. O'Byrne, "CAPL 1990 Operating Procedure - A Working Man's Guide" in Oil \& Gas Operating Agreements (Edmonton: Legal Education Society of Alberta, 1991). 
document have largely been ignored, with the expectation that others, with perhaps a more objective perspective, will write articles on specific aspects of the 1990 document.

\section{INTERPRETATION}

Article I continues to be comprised of two major parts - the definitions in Clause 101 and the miscellaneous boilerplate provisions found in Clauses 102 to 107. Many changes have been made to the Article in the 1990 document, mostly as the result of the thorough editing of the 1981 form. However, there have been a number of significant conceptual changes of which users must be aware.

(a) Abandonment Definition (Subclause 101(a)): There had been some uncertainty respecting the scope of the references to abandonment in the 1981 document. This was particularly the case with respect to the standard of site restoration, since the definition of "drilling costs" had contemplated that site restoration was distinct from abandonment. To eliminate that uncertainty, a definition of abandonment has been included. The references to the "Regulations" and the restoration of the wellsite to both the satisfaction of applicable governmental authorities and the reasonable satisfaction of the owner or occupier of the surface ensure that the term will not be construed narrowly, to apply only to the physical plugging of a well.

(b) Affiliate Definition (Subclause 101(c)): An exclusion has been added pertaining to security assignments, and a proviso has been added to the end of the definition with respect to the relationship between a partnership and the entities comprising the partnership.

(c) Authority for Expenditure Definition (Subclause 101(e)): It was generally accepted that an Authority for Expenditure ("AFE") must include sufficient detail to enable a party to appreciate both the nature and scope of an operation and the costs of its various phases. In practice, though, the perceptions of what constituted "sufficient detail" varied significantly.

The inclusion of this definition is largely a result of two cases which considered the nature of an AFE: Renaissance Resources Ltd. v. Metalore Resources Ltd. ${ }^{3}$ and Passburg Petroleums v. San Antonio Explorations Lid. and D. W. Axford \& Associates Ltd. ${ }^{4}$

The Renaissance case addressed the nature of a party's approval of an AFE under the 1974 CAPL Operating Procedure where the final costs were significantly greater than those estimated in the AFE. The non-operator had refused to pay its share of the overexpenditure, arguing that its approval of the AFE had only granted the operator the authority to conduct the operation within 
the amounts specified in the AFE. In dismissing that argument, the court held that the approval of an AFE under the 1974 document constitutes the authority of a party for the operator to conduct the operation described in the AFE, notwithstanding that the actual cost may differ greatly from the operator's estimate.

The Passburg case took this reasoning one step further. In that case, the operator drilled a directionally drilled well after obtaining the approval of the non-operators to drill what they believed to be a conventional well under the 1981 form. The costs of drilling that well were greater than had been included in the AFE, and the non-operators refused to pay the incremental cost of drilling the directionally drilled well. At trial, the court determined that the parties did not agree to participate in the directionally drilled well. The court then concluded that the non-operators were not required to pay the incremental cost. The operation described in the AFE was a condition of the approval, and the operator had deviated significantly from the authority which had been granted to it by the non-operators. ${ }^{5}$

Given the judicial recognition that the essence of the AFE is the operation, rather than the estimate of the associated costs, it was apparent that it was advantageous for both operators and non-operators to be more prescriptive in the 1990 document. The inclusion of the definition should help parties to avoid these types of problems in the future.

(d) Completion Definition (Subclause 101(h)): The 1981 document did not include definitions of "completion" and "equipping." Instead, it included detailed definitions of "completion costs" and "equipping costs," from which one had to surmise what had been meant by "completion" and "equipping." The 1990 document includes definitions of both "completion" and "equipping," and it has greatly simplified the definitions of "completion costs" and "equipping costs" by tying them to the cost of the applicable operation.

(e) Development Well Definition (Subclause 101(j)): The definitions of "development well" and "exploratory well" have been moved to Clause 101 from Clause 1001 of the 1981 document.

There has been a significant change from the 1981 definition, however, with respect to the nature of the relationship to the existing productive well. If the joint lands subject to the 1981 document only include rights to the base of the Cardium formation and the only productive interval within two miles of the proposed well location is the deeper Nisku formation, the 1981 form deems that a Cardium test would be a development well, notwithstanding that the interval is not productive within a two-mile radius of the well location. In order to

The Passhurg case also has serious implications for independent operations, as noted later in the examination of independent operations. 
minimize the arbitrariness of the distance test, the development well definition in the $\mathbf{1 9 9 0}$ document has been modified to limit the examination of productive intervals in offsetting wells to horizons and substances which are also included in the joint lands, such that the Cardium test in the preceding example would be an exploratory well under the 1990 document.

Drilling Costs Definition (Subclause 101(k)): The definition has been clarified with respect to the costs of obtaining surface access and constructing the roadways reasonably necessary for the drilling of a well.

(g) Equipping Definition (Subclause 101(l)): The scope to be given to "equipping" in the 1974 and 1981 versions of the CAPL Operating Procedure was unclear.

The applicable definition in the 1974 form was as follows:

\footnotetext{
"equipping costs" shall mean all costs incurred in cquipping a well beyond the wellhead including, without limiting the generality of the foregoing, the pump, the acquisition and installation of flow lines and production tankage and, in the case of a gas well. a heater or dehydrator or other hydrate control facility.
}

The corresponding provision in the 1981 document was as follows:

\begin{abstract}
"equipping costs" means with respect to a well, all moneys expended beyond completion to acquire and install equipment required to produce petroleum substances from the well including, without restricting the generality of the foregoing, the pump (or other artificial lift equipment), the acquisition and installation of flow lines and production tankage serving the well and where necessary a heater, dehydrator or other facility for the initial treatment of the petroleum substances produced from the well to prepare such production for transport to market, but specifically excluding costs incurred beyond the point of entry into a gathering system, plant or other common facility which is or will be operated pursuant to a separate agreement. ("equip," "equipping," "equipped" and other derivatives of equip, shall have corresponding meanings and relate to those operations in which equipping costs are anticipated or incurred.)
\end{abstract}

The major problem with those definitions was in attempting to determine whether and how they would apply with respect to tangible equipment serving more than one well. The task was particularly difficult when interpreting the 1981 document because of the general exception if the asset "is or will be operated pursuant to a separate agreement," as any production facility could be the subject matter of a separate agreement.

The definition of "equipping" in the 1990 document, on the other hand, is as follows:

"equipping" means the installation of such equipment as is required to produce petroleum substances from a completed well, including, without restricting the generality of the foregoing, a pump (or other artificial lift equipment), the installation of the flow lines and 
production tankage serving the well and, if necessary, a heater, dehydrator or other wellsite facility for the initial treatment of petrolcum substances produced from the well to prepare such production for transportation to market, but specifically excludes any such equipment, instaltation or facility that is (or is intended to be) a production facility.

The inclusion of the production facility provisions in the document has resulted in the clarification of the scope of the equipping definition, by specifically excluding any equipment or installation which "is (or is intended to be) a production facility." In effect, this qualification ensures that the equipping definition only applies to equipment which serves a single well.

(h) Market Price Definition (Subclause 101(s)): Article VI of the 1981 Operating Procedure had required a party selling production on behalf of a party which did not take in kind to sell that production "at the same price which the Operator receives for its own share of production or to purchase the same for its own account at the field price prevailing in the area." That Article had been appropriate at the time the 1981 document was written. However, major changes were required to the Article in the preparation of the 1990 form, given the surplus of available gas and a large variation in gas prices following deregulation of gas pricing in the mid-1980s.

The definition of "market price" was structured to attempt to address these problems in conjunction with the revised Article VI, and is as follows:

"market price" means the price at which petroleum substances are to be sold pursuant to Article Vl where a party does not take its share of petroleum substances in kind and separately dispose of the same. which price is not unreasonable, having regard to market conditions applicable to similar production in arm's length transactions at the time of such disposition, including, without restricting the generality of the foregoing. such factors as the volumes available, the kind and quality of petroleum substances to be sold, the effective date of the sale. the term of the sale agreement, the point of sale of the petroleum substances and the type of transportation service available for the delivery of the petroleum substances to be sold.

This definition has been included to reflect the major revisions which have been made to Article VI, and is designed to ensure that a non-taking party does not receive an unreasonable price for production sold on its behalf pursuant to Article VI. While the selling party has certain fiduciary obligations to the nontaking party with respect to such a sale, the definition places the onus on the non-taking party to demonstrate that the sale price was unreasonable, having regard to the market conditions at the time of the sale. This reverse onus mechanism ensures that the party so disposing of production is not required to investigate every opportunity to sell that production in an attempt to obtain the highest price available in the marketplace.

(l) Participating Interest Definition (Subclause 101(w)): Participating interest has been redefined, so that it pertains to a party's share of the costs of an operation, 
rather than to its interest in the joint lands. The latter is addressed through the inclusion of the new definition of working interest in Subclause 101(ff). The terms in the 1990 document correspond much more closely to the manner in which they are used in the oil and gas industry.

(m) Production Facility Definition (Subclause 101(z)): There had been a widely shared perception that the scope of the Operating Procedure was too narrow to enable the parties to take the actions reasonably necessary to conduct their business properly. As a result, a definition of production facility was added to the 1990 document, to be used in conjunction with the major revisions which have been included to reflect those concerns (Clauses 1021 and 1022 and Article $\mathrm{XIV}$ ), and is as follows:

"production facility" means, subject to Article XIII and Clauses 1021, 1022 and 1408, any facility serving (or intended to serve) more than one (1) well (including, without restricting the generality of the foregoing, any battery, separator, compressor station, gas processing plant, gathering system, pipeline, production storage facility or warchouse). which is:

(i) constructed or installed for the joint account;

(ii) owned exclusively by the parties in accordance with their respective working interests;

(iii) initially intended to be utilized exclusively with respect to the production, treatment, storage or transmission of petrolcum substances:

(iv) not used for fractionation of petroleum substances, sulphur extraction or separation of liquids by refrigeration; and

(v) not subject to a separate agreement governing the construction. ownership and operation of such facility:

and includes all real and personal property of every kind, nature and description directly associated therewith, excluding petroleum substances, the joint lands and the Operator's owned or leased equipment.

The definition is much narrower than the manner in which the term is typically used in an oil and gas industry context. The qualifications included in the definition exclude such typical facilities as refineries, cryogenic gas plants, acid gas or sulphur recovery facilities and sulphur forming, loading and remelting facilities. In essence, a production facility, as defined, will be a minor facility intended to serve the joint lands, which is owned exclusively by all or some of the parties and for which the parties have decided against the preparation of a separate construction, ownership and operating agreement ("CO\&O agreement").

The production facility is not required to be held by all of the parties in the percentages of their working interests. While only the parties may hold an interest in a "production facility," a production facility may be constructed or expanded as an independent operation pursuant to Clause 1021 or 1022. 
A facility which initially falls within the scope of the definition may subsequently cease to be a production facility. This would happen if the parties were later to enter into a separate $\mathrm{CO \& O}$ agreement or if that facility were to be used significantly with respect to production from other than the joint lands.

(n) Spacing Unit Definition (Subclause 101(cc)): The reference "in each zone from which such petroleum substances are to be produced" has been added to the end of subparagraph (ii) to clarify the definition, a change which will prove to be particularly useful as horizontal wells become more common.

There has been a general assumption that the normal Alberta spacing unit respecting a gas well is 640 acres in all zones in which the parties jointly hold the section. Since the parties are free to drill and produce a Viking gas well on the same section on which a Nisku gas well is located, it is clear that a production spacing unit has both an areal and stratigraphic component. Given the reference in the traditional definition to the three dimensional "area allocated to the well pursuant to the Regulations for the purpose of producing petroleum substances," the definition was certainly accurate as it stood, but the subtlety of the definition appeared not to have been appreciated by most users.

(o) Subclause 103(c): All of the versions of the CAPL Operating Procedure use terms such as "within" and "at least" when referring to a specific number of days. This Subclause has been included in the 1990 document to clarify the timing problems inherent in the use of such terms. It is based on the comparable provision in The Alberta Rules of Court.

(p) Clause 105: The definitions of "completion costs," "drilling costs," "equipping costs" and "operating costs" in the 1981 form included a series of derivatives at the end of the definitions. The inclusion of this Clause ensures that terms such as "abandon," "abandoning," and "abandoned" can be used in the context of the definition of "abandonment."

(q) Clause 107: The conflicts provision in the 1981 document had been a simple statement in Clause 304. The conflicts provision in the 1990 form has been moved to Article I, and it has been expanded significantly to address two material flaws found in the typical conflicts provision. The modification states that the working interests of the parties and the allocation of legal responsibility provided in the Operating Procedure shall continue to apply among the parties, notwithstanding the registered interests in the documents of title and any regulatory provisions respecting legal responsibility for activities conducted under the Operating Procedure.

If the registered interests in the title documents do not correspond to the working interests (as is often the case), the traditional conflicts provision literally states that the working interests of the parties are the registered interests in the title documents because of the inconsistency between the title documents and the Operating Procedure. 
The liability reference is included because of the degree to which the title documents and the regulations require a lessee or well licensee to assume legal responsibility for losses. Although that allocation of responsibility may be in the public interest, it is clear that the provisions of the Operating Procedure allocating legal responsibility among the parties, such as Article IV, should continue to govern the relationship of the parties with respect to the apportionment of that responsibility among the parties.

\section{APPOINTMENT AND DUTIES OF THE OPERATOR}

This section of the paper will address three general topics: the role of the operator under the Operating Procedure; the appointment and replacement of the operator, as addressed in Article II; and the duties of the operator, as delineated in Articles III and VII.

\section{A. ROLE OF THE OPERATOR}

The operator's role in the management of joint operations and the joint lands is addressed philosophically in Clause 301 of each of the 1974, 1981 and 1990 CAPL Operating Procedures.

Clause 301 of the 1974 form had provided the operator with a broad authority, having stated, "[t]he Operator is hereby delegated the exclusive control and management of the exploration, development and operation of the joint lands for the joint account ...."

Given the degree to which this provision literally tended to equate the position of operator with a greater form of ownership, this provision was amended significantly in the 1981 document, by eliminating the reference to "exclusive control" and by adding a general duty to consult. The comparable portion of Clause 301 of that document stated:

The Operator is hereby delegated the control and management of the exploration, development and operation of the joint lands for the joint account, provided it shall consult with the Joint-Operators from time to time with respect to decisions to be made for the exploration, development and operation of the joint lands, and keep the Joint-Operators informed with respect to operations planned or conducted for the joint account.

The 1990 document continues the trend of providing the non-operators with additional control over the management of joint operations. Subclause 301(a) of the document states:

The Operator shall consult with the Joint-Operators from time to time with respect to decisions to be made for the exploration, development and operation of the joint lands and the construction, installation and operation of any production facilities, and the Operator shall keep the Joint-Operators informed with respect to operations planned or conducted for the joint account. Subject to the provisions hereof, the Operator is hereby delegated the management of the exploration, development and operation of the joint lands and the construction, installation and operation of any production facilities for the joint account on behalf of the Joint-Operators. 
Other provisions of the 1990 document reinforce the operator's role as the manager of the property on behalf of the interest holders. Subclause 202(b), for example, enables the non-operators to remove the operator fairly easily without cause.

\section{B. THE APPOINTMENT AND REPLACEMENT OF THE OPERATOR}

Article II of the 1990 document is comprised of three major components: the replacement and challenge of the operator, the appointment of a new operator and the assignment of operatorship.

\section{The Replacement of Operator (Clauses 202-205)}

The 1990 document continues to address both the immediate and delayed replacement of operator mechanisms in Clause 202. Major revisions have been made to the Clause, though, largely to reflect recent cases pertaining to the enforceability of paragraph 202(a)(i) of the 1981 form.

As evidenced by the case of Norcen Energy Resources Limited and Prairie Oil Royalties Company, Ltd. v. Oakwood Petroleums Lid., courts may be willing to protect an insolvent operator from the imposition of such a provision, even though that party had quite willingly accepted the provision at the time it executed the document. The case pertained to an interpretation of section 11 of the Companies' Creditors Arrangement Act, ${ }^{7}$ the purpose of which is to attempt to allow an insolvent company to continue as a going concern in the hope that it will be able to overcome its major financial difficulties or make an arrangement with its creditors. Norcen was not a creditor of Oakwood in the case, and the court interpreted section 11 as giving it the authority to affect the contractual relations between the insolvent party and a non-creditor. It granted a temporary stay which prevented Norcen from assuming operatorship pursuant to Clause 202 of the 1981 document, even though the court recognized that Oakwood had been insolvent for some time. The case was not appealed.

This protection from the application of Clause 202, however, would not apply if the operator were making a proposal to creditors under the Bankruptcy Act, ${ }^{8}$ as was held in Tri-Star Resources Ltd. v. J.C. Int. Petroleum Ltd.

Mostly as a result of the Norcen case, the 1990 provision has been broadened to include references to "debtor relief protection under applicable legislation" and the Companies' Creditors Arrangement Act. In addition, the 1990 provision must be read in conjunction with the new waiver of relief provision, Clause 2807 , whereby a party waives certain rights it may otherwise have at law or under the regulations with respect to the application of the provisions of the 1990 document. Although those changes cannot

R.S.C. 1985, c. C-36.

R.S.C. 1985 , c. B-3.

[1987] 2 W. W. R. 141 (Alta. Q.B.). 
operate to eliminate the court's jurisdiction to override the terms of the contract, they may cause a court to be less likely to alter the contract.

The court also addressed the nature of the reference to insolvency in the Norcen case. Oakwood had attempted to argue that it was commercially solvent with respect to day-today matters relating to the specific agreement and that the Operating Procedure provisions contemplated only commercial insolvency. The court held that insolvency was to be given its normal meaning in the interpretation of the 1981 CAPL provision, though, and paragraph (i) has been amended to reflect the court's interpretation of the intention of the previous provision. However, a party would require a great deal of information about the operator's business affairs if the issue of the operator's insolvency were to be considered by a court, and it would be unlikely to receive any significant cooperation from the operator prior to the commencement of an action. It would therefore often be very difficult to determine whether or when insolvency had occurred in practice.

The reference to the appointment of a receiver should also be noted. Following the appointment of a receiver, the lender will generally provide the funds required to ensure that the debts are then paid as they become due, such that the onus on the non-operators to prove insolvency would then be more difficult.

Subclause 202(b) was also amended significantly, with the major change being the replacement of the $10 \%$ working interest requirement in paragraph 202(b)(i) of the 1981 document, with a no-cause removal of operator mechanism. In essence, the no-cause removal of operator mechanism enables two or more joint-operators holding greater than a 50\% working interest to remove the operator without having to demonstrate any failure of the operator in the performance of its obligations. The mechanism is subject to an additional qualification, in that a non-operator holding more than a $66 \%$ working interest has the right to become the operator by giving notice to the other parties, assuming that it would not be disqualified from becoming the operator pursuant to paragraph 202(a)(i).

To some degree, this provision is a reflection of the Norcen case, in that it is intended to provide the non-operators with another means to remove a distressed operator. For the most part, however, the paragraph reflects both the fundamental flaws in the traditional challenge mechanism and the evolving philosophy that the operator is ultimately the representative of the joint-operators, to serve in that capacity only at their leisure.

The traditional challenge clause, Clause 203, limits the challenge to an offer to conduct joint operations on "more favourable" terms and conditions than the operator. This poses a serious, if not insurmountable, obstacle to the challenger. Since one is unable to quantify qualitative changes, that provision seems limited to financial terms. However, how could a challenger give any more than its best cost estimate when the costs of exploration are a function of such factors as weather conditions, exploration success (testing costs), mechanical difficulties, the demand for equipment and inflation? A challenge on the basis of terms and conditions, therefore, might only be the right to challenge on the basis of overhead rates in practice. Moreover, a challenge on the basis of financial terms and conditions ignores the consideration that the basis of a challenge may be the operator's technical, rather than cost performance. Even assuming that a 
challenge fell within the scope of Clause 203, one huge obstacle would remain, since the operator would still be able to retain its position by agreeing to accept the terms in the challenge notice.

Paragraph 202(b)(i) is much stronger than the traditional challenge mechanism, since it enables the non-operators to remove an operator against its will. Given the significant costs potentially associated with the removal of an operator during the development phase, the potential for the disruption to operations and the business considerations associated with such a removal, the most practical impact of this provision is to reinforce the operator's accountability to the owners for its performance. Although quite different from the traditional challenge mechanism, it should be remembered that the use of a voting procedure/no-cause challenge mechanism is used in conventional unit agreements, the 1988 CAPL Frontier Operating Procedure and many international joint operating agreements.

One might argue that this provision should provide the operator with the right to attempt to rectify its perceived defaults or shortcomings. However, the problem with that suggestion would be the difficulty one would have in trying to quantify an acceptable performance standard in the document for what would usually be a qualitative problem. Although the 1990 document does not address that issue, one would anticipate that the parties would discuss the possibility of rectification in practice before resorting to the removal of the operator.

Two other material changes were made to these Clauses. Paragraph 202(b)(ii) now requires the operator not only to commence rectifying the default, but also to continue diligently to remedy the default. Clause 204 was altered slightly, by eliminating the requirement that an operator only be permitted to resign after having served as operator for at least one year.

\section{The Appointment of a New Operator (Clauses 206-208)}

The only significant change to these Clauses was the inclusion of a provision in Strbclause 206(a) which enables a non-operator holding more than a $66 \%$ working interest to become the operator upon the resignation or replacement of the previous operator, unless that non-operator would then be subject to replacement pursuant to paragraph 202(a)(i).

\section{The Assignment of Operatorship (Clause 209)}

The 1981 document was silent on the operator's ability to transfer operatorship when it assigned all or a portion of its interest in the joint lands. This deficiency did not become apparent until the late 1980s, when operators regularly began to attempt to assign operatorship as a result of corporate reorganizations and industry rationalization programs, and has since been perceived as a problem by both non-operators and operators.

Non-operators were alarmed by operators' attempts to assign operatorship as if it were just another asset owned by them, particularly since a new operator could not be 
challenged until two years following the date it became the operator. Non-operators regarded operatorship as something which was personal to the party serving as operator. If that party were no longer prepared to serve in that capacity, a new operator should be selected by the parties pursuant to Clause 206.

Operators were also disturbed by this uncertainty. Purchasers were generally proceeding on the assumption that they would become the operator of a purchased property, something which was particularly important as companies continued to adapt to the financial uncertainties respecting the oil and gas industry. Moreover, non-operators had occasionally attempted to use the corporate reorganization of an operator as a vehicle to attempt to replace the operator in circumstances in which the corporate reorganization would have no impact on the manner in which the property was to be managed.

Clause 209 addresses the assignment of operatorship, so that the rights of the nonoperators are clear. A proposed assignment of operatorship to other than an affiliate requires the approval of the parties pursuant to Clause 206. However, operatorship may be assigned to an affiliate when the working interest is also being assigned, as there would be no anticipated impact on joint operations with respect to a transfer from ABC Ltd. to its affiliate, $A B C$ Resources Inc. If the non-operators were sufficiently troubled with the operator's performance in the latter case, they presumably would have used their other rights to remove the operator. If there were a concern that the affiliate were a "shell company," the parties could easily replace it pursuant to paragraph 202(b)(i) in cases in which the non-operators held a majority interest, and they would have immediate access to Clause 203 in all cases.

\section{DUTIES OF THE OPERATOR}

The principal duties of the operator are prescribed by Clauses 302-312 and Article VII. Ignoring the insurance requirements in Clause 311 , the only significant changes in Clauses 302-312 of the 1990 document have been with respect to the addition of Subclauses 309(b) - (d).

Subclause 309(b) requires the operator to consult with the other parties with respect to any material decisions which are required to be made to maintain any of the title documents in good standing, including such matters as continuation or grouping applications. The operator is also required to provide copies of related correspondence to the non-operators in a timely manner.

Subclause 309(c) is a simple lease selection mechanism, designed for the situation in which the interests in the affected lands are uniform. Although suitable for a case in which a farmee has earned all of the licence lands for drilling a well which validated less than an entire licence, it will often be desirable to include a lease selection provision in the head agreement where the interests are more complex, so that the provision in the head agreement overrides this Subclause.

Subclause 309(d) corrects a deficiency in the 1981 form. Assume that sufficient work had been conducted with respect to a licence or permit to enable the parties to select 
leases for only a portion of the lands subject to that document and a party wished to drill an additional well on the lands within the time period prescribed by Clause 1010. There was generally a problem in determining the manner in which Clause 1010 would apply, as it would be unlikely that the parties would have determined the lands to be included in the lease selection at that early date. The Subclause enables a party to cause the parties to make a lease selection earlier than the date required by Subclause 309(c), for the purposes only of crystallizing the positions of the parties with respect to Clause 1010 . The parties retain the flexibility of changing this selection at a later date if they so agree, however, since the actual lease selection would not be made to the Crown until the date required by the regulations.

The only significant change in Article VIl pertains to the manner in which AFEs are processed. Subclause 701 (a) states that an AFE will be void unless it is approved by all of the parties within 45 days of its submission to the joint-operators, such that a party will not be bound by an AFE for a prolonged period while waiting for another party to approve the AFE. To ensure that the parties are aware of the status of an AFE, the operator is required to advise the parties promptly once the status of the approval of the AFE by the parties is clear. Assuming that all of the parties approve the AFE, Subclause 701(b) ensures that the parties are not bound indefinitely by an approved AFE. It provides that the AFE is void if the operation is not commenced within the later of 120 days following the issuance of the AFE or 45 days following the estimated date of commencement specified therein, subject to the qualification that the operation is to be commenced within 180 days of the issuance of the AFE in any event.

\section{INSURANCE}

The insurance provisions in Clause 311 of the 1981 and 1990 documents are similar in approach, as they require the parties to elect to use one of two alternates Alternate $A$, which requires the operator to obtain specified policies for the joint account, and Alternate $\mathrm{B}$, which requires the operator to obtain for the joint account only those policies which are required to be maintained pursuant to the regulations. There have been a number of substantive changes made in Clause 311 of the 1990 form, however, with the most significant being as follows:

(a) All insurance policies obtained for the joint account are to be maintained for the benefit of not only the parties, but also "their respective Affiliates, directors, officers, servants, consultants, agents and employees;"

(b) The specific Employers' Liability Insurance requirement in paragraph $A(a)(i)$ of the 1981 form has been excluded because of the reference to that coverage within paragraph $\mathrm{A}(\mathrm{a})(\mathrm{ii})$ of the 1990 document;

(c) Subclause 311 (b) requires the operator to advise the other parties if the specified policies or coverages are, in the operator's reasonable opinion, unavailable or available only at an unreasonable cost; 
(d) Subclause 311(c) restricts the operator's ability to charge to the joint account payments made by it with respect to losses or claims arising out of joint operations. It can only charge those payments to the joint account if the payment has been authorized by the applicable insurers or is otherwise authorized under the Operating Procedure;

(e) Subclause 311 (d) requires the operator to ensure that an insurance policy maintained for the joint account is primary to the other coverages held by the parties and that the policy will survive the default or bankruptcy of the insured for claims arising before that time;

(f) Subclause 311 (e) requires a party to ensure that the policies of insurance maintained by it include waivers of subrogation against not only the other parties, but also "their respective Affiliates, directors, officers, servants, consultants, agents and employees;" and

(g) Subclause $311(f)$ requires the operator to notify the other parties of loss or damage as soon as practicable following the discovery of the loss or damage and to provide the other parties with such assistance as they may require to substantiate the loss or damage in their insurance claims.

\section{INDEMNIFICATION AND LIABILITY}

The format of Article IV of the 1990 document is similar to Article IV of the 1981 form. Clause 401 addresses the extent of the operator's legal responsibility for losses arising out of joint operations, and Clause 402 addresses the indemnification of the operator with respect to those of such losses which are borne for the joint account. Clause 401 also continues to address liability and indemnity distinctly, to avoid any risk of the result in Mobil Oil Canada, Ltd. v. Beta Well Service LId." In considering a provision drafted by the plaintiff in that case, the court determined that the provision was solely an obligation to indemnify, since it did not clearly distinguish between the liability and indemnification obligations.

A number of substantive changes have been made to the Article in the 1990 document, though, with the most notable being as follows:

(a) A "notwithstanding" reference has been included at the beginning of Clause 401, so that it is clear that Clause 401 overrides Clauses 303 and 304 . Clause 303 states that the operator is an independent contractor, and Clause 304 imposes a general obligation on the operator to conduct operations in accordance with good oil field practice. In the absence of this reference, it is possible that the overall standards prescribed by Clauses 303 and 304 could override Clause 401, which basically limits the operator's general liability to gross negligence or wilful misconduct. This is because the loss may be one which is not addressed by the 
specific standard of legal responsibility in Clause 401, such that it otherwise may have been open to argue that the general standard was intended to prevail.

The notwithstanding reference is limited to Clauses 303 and 304, however. A general notwithstanding reference, in effect, would require the non-operators to prove that any loss pertaining to the operator's breach of the contract, in its capacity as the operator, was due to the operator's gross negligence or wilful misconduct;

(b) The reference "whether contractual or tortious" has been added to the introduction of Clause 401 to eliminate any possibility that a court would interpret the provision to apply solely to tortious liability;

(c) The reference "whether negligent or otherwise" has been added to the introduction of Clause 401 to ensure that an operator would not be held solely responsible for its own negligence. In the absence of this reference, an operator would have to argue that the special provisions pertaining to gross negligence imply that losses applicable to negligence are to be borne for the joint account;

(d) A "when and to the extent" reference has been added to the beginning of Subclause 401(b), in the place of the "when" test used in the 1981 document. This ensures that a loss which is due to the operator's gross negligence or wilful misconduct and other causes can be apportioned to the applicable causes, and it also enables the operator to raise the issue of contributory negligence;

(e) There is a proviso at the end of Clause 401 which excludes the operator's responsibility respecting the loss or delay of production. This exclusion is relatively new to North American agreements, and was used in the 1988 CAPL Frontier Operating Procedure. The concept has received significant support with respect to international offshore projects, where proponents argue that the magnitude of a potential loss of this type is such that the assumption of operatorship in that environment would not be viable without the exception; and

(f) Clause 402 has been altered, so that the Joint-Operators are required to indemnify not only the operator, but also "its Affiliates, directors, officers, servants, consuitants, agents and employees." There is significant doubt that the reference to the additional persons would be effective, though, as Greenwood Shopping Plaza Ltd. v. Beattie et al." held that a person who is not a party to a contract can neither sue nor rely upon it to protect himself from liability, except in case of agency or trust. ${ }^{12}$

The British Columbia Court of Appeal recently considered the issue of an employee's liability where a limitation clause had been included in a contract between the employer and a customer in London Drugs Limited v. Kuehne \& Nagel International Ltd. et al., [1990] 4 W.W.R. 289, however, and held that the employees were entitled to the benefit of the limitation provision in the contract, even though they were not parties to the contract. The case has been appealed to the Supreme Court of Canada 


\section{FINANCIAL PROVISIONS}

The financial provisions of the 1990 document continue to be comprised of Clause 301 and Article V. However, fundamental changes have been made to these provisions in light of the difficult economic conditions which have generally affected the oil and gas industry since the mid 1980 s.

This section of the paper will focus on four particular topics: expenditure limitations, advances, default and remedies and commingling of funds.

\section{A. EXPENDITURE LIMITATIONS (CLAUSE 301)}

Clause 301 of the 1974, 1981 and 1990 documents addresses the limitations on the operator's ability to make expenditures for the joint account. This provision has evolved significantly over time, however. The applicable portion of Clause 301 of the 1974 form, for example, simply stated:

The Operator shall not make an expenditure for any single undertaking the total estimated cost of which is in excess of Ten Thousand Dollars $(\$ 10000)$ without a written authority of expenditure from JointOperators, unless the expenditure is considered by Operator to be necessary by reason of an event endangering life or property.

This provision was altered significantly in the 1981 form, by increasing the discretionary authority, by better defining the philosophy of the authority and by referring to the operator's obligation to issue a Supplementary AFE in certain circumstances. The applicable portion of the Clause 301 of the 1981 form was as follows:

Subject to Clause 304, the Operator shall be entitled to make or commit to such operating expenditures for the joint account as it shall consider necessary and prudent in order to carry on a good and workmanlike operation for the joint account, provided the Operator shall not make or commit to an expenditure for the joint account for any single operation, the lotal estimated cost of which is in excess of twenty-five thousand $(\$ 25,000)$ dollars without a written Authority for Expenditure from JointOperators, unless the expenditure is considered by Operator to be necessary by reason of an event endangering life or property. Particulars of each such event shall be reported promptly to the JointOperators.

Notwithstanding the foregoing, if the Operator while conducting any single operation for the joint account, which operation is covered by a written Authority for Expenditure, incurs or expects to incur expenditures for the joint account in excess of the total amount authorized in writing by the JointOperators for that operation plus ten (10\%) percent thereof, the Operator shall forthwith so advise the Joint-Operators and submit for their approval a written supplementary authority for such excess expenditures. 
The comparable provisions of the 1990 document are Subclauses 301(b) and (c), which state:

(b) The Operator shall be entitled to make or commit to such expenditures for the joint account as it considers necessary and prudent in order to conduct a good and workmanlike operation on the joint lands for the joint account. However, the Operator shall not make or commit to an expenditure for the joint account for any single operation. the total estimated cost of which is in excess of twenty-five thousand (\$25 000) dollars, without an approved Authority for Expenditure from the Joint-Operators, unless the expenditure is reasonably considered by the Operator to be necessary by reason of an event endangering life or property or is required by the Regulations and failure to make such expenditure could result in the prosecution of the Operator thereunder. If the Operator is required to make such an expenditure, it shall promptly advise the Joint-Operators of the nature of such event or requirement and the expenditure anticipated to be associated therewith.

(c) Approval of an Authority for Expenditure by a party shall constitute that party's approval of all expenditures necessary to conduct the operation described therein, subject to the provisions of Article IX. However, if the Operator incurs or expects to incur expenditures with respect to a joint operation which would exceed by more than ten percent (10\%) the total amount estimated in the AFE therefor, the Operator thereupon shall, for informational purposes only, forthwith advise the Joint-Operators of such overexpenditure, the Operator's explanation therefor and the Operator's revised estimate of the cost of such operation. The Operator thereafter shall provide estimates of current and cumulative costs incurred for the joint account with respect to such operation. Such estimates shall be provided on a daily basis where practical, but in any event at intervals of not greater than ten (10) days until the operation is completed.

Subclause 301 (b) is similar to the corresponding portion of the 1981 provision. The operator is provided with the discretionary authority to make expenditures of up to $\$ 25$ 000 for the joint account with respect to a single operation without requiring an approved AFE. The operator may also make additional expenditures for the joint account without an approved AFE, if reasonably considered necessary by the operator for the protection of life or property. One significant change has been made to the Subclause, though. The operator has also been empowered to make an additional expenditure for the joint account without an approved AFE if the expenditure is required to be made pursuant to the regulations and failure to make the expenditure could result in the prosecution of the operator thereunder.

Subclause 301(c), on the other hand, has been changed drastically, mostly as a result of the Renaissance case and the ambiguity inherent in the comparable portion of the 1981 provision. As noted previously, the Renaissance case addressed the issue of whether a party's approval of an AFE under the 1974 form constituted that party's election to pay its proportionate share of the cost of that operation or only its election to pay its share of the cost specified in the AFE, in circumstances in which a non-operator's share of the cost of an operation significantly exceeded those specified in the AFE. After considering leading American cases on the issue, the court determined that the approval of the AFE constituted the authority of a party for an operator to conduct the operation described 
therein, notwithstanding that the actual cost may differ significantly from the operator's estimate. $^{13}$

The intention of the last portion of Clause 301 of the 1981 document was arguably consistent with the determination in the Renaissance case, even though the 1981 provision was ambiguous. The applicable portion of Clause 301 in the 1981 form stated that an operator was required to submit a Supplementary AFE to the non-operators "for their approval" with respect to overexpenditures greater than the permissible $10 \%$ overrun. However, the Clause did not provide for the scenario in which a party refused to approve the Supplementary AFE. The rationale for this construction seems to have been to encourage the operator to issue a supplementary estimate in a timely manner, rather than to provide a mechanism for a party to opt out of the operation. The latter presumably would have been addressed specifically had that been the intention.

Given the determination in the Renaissance case, the ambiguity in the 1981 provision and the likelihood that more companies would attempt to use the 1981 provision as a vehicle to opt out of operations in a volatile economic climate, Subclause 301 (c) has been rewritten. It provides that a party's approval of an AFE constitutes that party's approval of all expenditures necessary to conduct the operation described in the AFE, subject to the provisions of Article IX of the Operating Procedure. If the operator anticipates that it will incur expenditures exceeding more than $110 \%$ of the amount estimated in the AFE, the operator shall, for informational purposes only, advise the non-operators of the overexpenditure, the operator's explanation therefor and the operator's revised estimate of costs. In addition, the operator is required to provide estimates of current and cumulative costs incurred for the joint account on a current basis. Although there has not been significant industry objection to this principle to date, it is likely that some parties will amend this Subclause with respect to drilling operations in certain high cost operating environments.

\section{B. ADVANCES (CLAUSE 503)}

Subclause 503(a) entitles the operator to require an individual party to secure payment of its share of the costs of an operation to be conducted for the joint account "in a manner satisfactory to the Operator," a reference which is quite similar to that used in Clause 503 of the 1981 form. The new Subclause differs significantly from the 1981 provision, though. It expressly contemplates the possibility that a party might do this by establishing an irrevocable letter of credit in favour of the operator with respect to that

13. Supra, note 3. The court did not have to decide, however, whether a non-operator should be entitled to any relief if the operator had been fraudulent or grossly negligent in the preparation of the AFE. or if the operator had realized that actual costs would differ significantly from a cost estimate in the period between the issuance of the AFE and the commencement of the operation. In fact, the judgement of Kidd J., [ 1984] 4 W.W.R. 430 at 455 (Alta. Q.B.), stated, "I see no reason why, in the proper case, it would not be open to a joint-operator to allege negligence in the preparation of an AFE and/or the drilling of a well." 
party's share of costs and by including safeguards to minimize the likelihood that an operator would require all of the non-operators to obtain letters of credit. ${ }^{14}$

The acceptability of the provision will ultimately be a function of the manner in which operators use the provision. If operators were often to request financially viable nonoperators to obtain letters of credit as a matter of principle, it is probable that many companies would require the deletion of the provision or simply refuse to obtain the letter of credit. If, on the other hand, operators were only to use this discretion in circumstances in which there were a reasonable doubt respecting a non-operator's ability to fund its share of costs, it is likely that only a minor modification might be required when the Operating Procedure is next revised.

The second notable change is that the Clause has been modified so that it applies to capital costs, rather than to both costs and expenses. The provision does not apply to operating expenses, as they are covered by Clause 105 of the 1988 PASC Accounting Procedure.

The third change is likely to be the most significant in practice. Clause 503 of the 1981 document had enabled the operator to require the non-operators to advance their share of costs anticipated to be incurred in a calendar month, even though those costs might not be paid until some time following that month. Subclause 503(b) of the 1990 form has been modified to enable the operator to require the non-operators to advance only costs which are anticipated to be paid in the calendar month to which the advance pertains.

\section{DEFAULT AND REMEDIES (CLAUSE 505)}

The financial difficulties which have generally affected the oil and gas industry since the mid-1980s have demonstrated that there were a number of major deficiencies in Clause 505 of the 1981 document. As a result, the following significant changes were made to the Clause in the 1990 form:

(a) Subclause 505(a) has been structured so that the operator's claim arises when the Operating Procedure becomes effective, rather than when the expenditures are made. Notwithstanding this construction, the operator's lien generally may not be the subject of a security notice, such that the actual priority of the operator's lien usually will be determined by the common law rules on priorities. That being the case, it is unlikely that the provision would be effective against lenders with registered security notices, even though those lenders were aware of the probability that an Operating Procedure were in effect;

14. The operator may only draw on the letter of credit in the same manner and at the same time intervals as otherwise provided in the Operating Procedure. The operator, therefore, is unable to use the letter of credit as a financing vehicle for its expenditures. 
(b) The operator's lien applies to all costs and expenses incurred for the joint account, not only costs and expenses pertaining to joint operations, as was the case in Subclause 505(a) of the 1981 document;

(c) The operator's lien attaches to the joint lands and any production facilities pertaining to the joint lands. The inclusion of production facilities in the 1990 form expands the remedies available to the operator;

(d) All interest references in the 1990 document are tied to paragraph 505(b)(i). That paragraph also corrects a number of flaws found in the traditional interest provision. That provision had not specified whether interest was compound or simple, the frequency of computation and the fact that the rate was a per annum rate. Moreover, the inclusion of the "regardless" phrase at the end of the paragraph should eliminate the risk that prior notice of the intention to charge interest is required under the traditional interest provision, as was held in the Renaissance case;

(e) The withholding of rights specified in paragraph 505(b)(ii) no longer requires 30 days notice of default before the operator can use the remedy. The remedy has also been modified to state that the defaulting party's rights are to be restored to it upon rectification of the default;

(f) An express right of set-off has been included as paragraph 505(b)(iii). While the remedy is basically a codification of a party's rights at common law, it was included so that a party's non-legal personnel would be aware of the possibility of using this remedy;

(g) A liquidated demand mechanism has been included as paragraph 505(b)(iv). It provides the operator with certain legal procedural advantages in the enforcement of a claim, as the claim is in debt. This paragraph ensures that the operator would not be required to prove that the applicable work was done;

(h) The assignment of proceeds mechanism in paragraph $505(\mathrm{~b})(\mathrm{v})$ has been clarified to provide that the assignment of proceeds is limited to the amount of the default and the accrued interest applicable thereto;

(i) A number of significant changes have been made to the seizure and sale mechanism in paragraph 505(b)(vi). The operator is required to provide the defaulting party with at least 10 days prior notice of any sale, while there was no minimum notice requirement in the comparable 1981 provision. The 1981 provision had been silent on the responsibility of the operator to give any consideration to the maximization of the proceeds applicable to the interest of the defaulting party. The 1990 provision, on the other hand, requires the operator to sell the property for such a price and on such terms as the operator determines are reasonable, having due regard to the possible recovery of funds for the defaulting party in excess of the amount owed by it, including accrued interest. The 1990 provision also states that the sale of the property shall be without 
prejudice to the operator's claim for deficiency if the proceeds applicable to the sold interest are less than the amount owing by the defaulting party; and

(j) Subclauses 505(c), (d) and (e) are new provisions. Subclause 505(c) is an attempt to prevent the Interest Act ${ }^{15}$ from operating to merge a judgment of principal and interest. It is unclear, though, whether a court would consider itself bound by this provision, notwithstanding the new waiver of relief provision (Clause 2807). Subclause 505(d) provides that the operator's records shall constitute prima facie proof of the existence of a financial default, subject to audit rights. Subclause 505(e) provides that the non-operators may appoint a party to act as their representative to exercise the remedies otherwise available to the operator if the operator were the defaulting party.

\section{COMMINGLING OF FUNDS (CLAUSE 507)}

The commingling of funds provision of the 1981 document was Clause 507, which stated:

The Operator may commingle with its own funds the moneys which it receives from or for the account of the Joint-Operators pursuant to this Operating Procedure.

In light of the increasing number of financially distressed operators, some commentators had argued that agreements should require operators to hold funds in distinct trust accounts because of the view that creditors could otherwise seize funds held for the joint account in the event of an operator's insolvency. However, the Alberta Court of Appeal decided in Bank of Nova Scotia v. Societe General (Canada) et al. ${ }^{16}$ (usually referred to as the Sorrel case) that there is a trust relationship imposed when the conventional commingling clause of the 1981 CAPL Operating Procedure is used, since the intention that the operator acts for the benefit of the non-operators pervades the entire document.

The provision has been expanded to reflect that decision, with Clause 507 of the 1990 document being as follows:

The Operator may commingle with its own funds the moneys which it receives from or for the account of the Joint-Operators pursuant to this Operating Procedure. Notwithstanding that moneys of a JointOperator have been commingled with the Operator's funds, the moneys of a Joint-Operator advanced or paid to the Operator, whether for the conduct of operations hereunder or as proceeds from the sale of production under this Operating Procedure, shall be deemed to be trust moneys, and shall be applied only to their intended use and shall in no way be deemed to be funds belonging to the Operator, other than in its capacity as the Joint-Operators' trustec.

16. [1988] 4 W. W. R. 232 (Alta. C.A.) [hereinafter "Sorrel"]. 
However, the Sorrel case addressed a fact situation in which the lender was not the same institution as that with which the funds were deposited. Usually, funds would be on deposit with the lender, such that the typical lender may have rights of set-off which would prevail over the claims of the non-operators unless the lender knew or ought to have known that the funds were held in trust for the joint-operators.

Since the scope of that decision is still unclear, prudent non-operators should continue to monitor their non-operated properties for indications that an operator may have serious financial difficulties. It may be attractive to consider replacing such an operator pursuant to Clause 202 or 203. In the alternative, it may be desirable to use the leverage provided by those provisions to require the operator to maintain a separate trust account for the project or to hold joint account moneys at a bank to which the operator is not indebted.

\title{
VII. MARKETING
}

The marketing provisions of the 1990 document are drastically different from those which had been included in Article VI of the 1981 form, mostly as a result of the new marketing environment which followed the deregulation of petroleum and natural gas prices in the mid-1980s.

The principal marketing provision in the 1981 document was Clause 602 , which stated:

\begin{abstract}
When and so often as a Joint-Operator shall fail or refuse to take in kind and separately dispose of its proportionate share of any production, the Operator shall have the authority, revocable by that JointOperator at will (subject to cxisting sales contracts), to sell for the account and at the expense of that Joint-Operator its proportionate share of production to others at the same price which the Operator receives for its own share of the production or to purchase the same for its own account at the ficld price prevailing in the area. All sales made by the Operator of a Joint-Operator's share of production as aforesaid shall be for such periods of time only as are consistent with the minimum needs of the industry under the circumstances but in no event shall any contract for the sale of the Joint-Operator's share of production be made for a period in excess of one (1) year.
\end{abstract}

The provision had seemed satisfactory in the 1970s and the early 1980s, when markets were readily available for gas production and prices were regulated. The problems with the provision quickly became apparent, though, when there was a surplus of available gas and a large variation in gas prices following deregulation. A non-operator without a long term, full price contract which took in kind was usually forced to sell into the heavily discounted industrial market. An operator with a long term, full price contract, therefore, faced the risk that a non-operator without such a contract would prefer to have the operator market its production, rather than sell its own production into the industrial market. Assuming that the operator were meeting its deliverability requirements, the former provision could require the operator to displace its own production to sell a nonoperator's share of production under its contract. In the alternative, the operator could purchase the non-operator's production at "the field price prevailing in the area," whatever that meant, at a time when prices for similar production varied drastically! 
Another major irritant to parties which were required to market another party's share of production was the fact that the 1981 form did not provide them with any compensation for having so marketed the non-taking party's share of production. ${ }^{17}$

Article VI of the 1990 document addresses those problems and will be considered under four general headings: the ownership of production, the disposition of production where a party does not take in kind, the marketing fee and the miscellaneous marketing provisions.

\section{A. THE OWNERSHIP OF PRODUCTION (CLAUSE 601)}

Clause 601 of the 1990 document is consistent in principle with Clause 601 of the 1981 form. The parties have the right, but not the obligation, to take in kind, such that the "remedies" applicable where a party does not take in kind are limited to the marketing options prescribed by Clause 602 . Two minor deficiencies in the 1981 Clause have been corrected, though.

The first was that the 1981 Clause had been silent on the point at which the parties were to take production in kind. The 1990 Clause addresses that issue, and states that the parties shall have the right to take their respective shares of production in kind at the point at which production volumes are measured under the regulations - the first point of measurement.

The second was that the 1981 Clause ignored the responsibility of a non-operator to advise the operator of its marketing arrangements in sufficient detail to enable the operator to fulfil its obligations to transfer possession of production. As an operator without this information might dispose of a non-taking party's share of production in a much different manner than would otherwise be the case, the 1990 Clause requires the non-operators to provide the operator with this information.

\section{B. THE DISPOSITION OF PRODUCTION WHERE A PARTY DOES NOT TAKE IN KIND (CLAUSES 602 and 603)}

As noted previously, fundamental changes were made to Clause 602 to reflect the new marketing environment which has evolved since the mid-1980s. Despite these changes, the foundation of Clause 602 of the 1981 and 1990 documents is the same. The operator is given a limited right to dispose of a non-taking party's share of production, since production generally could not otherwise be taken from the applicable well. In considering the limitations which were appropriate to place on an operator's ability to

17. Some have attempted to argue that the producing well overhead, such as that in Clause 302 of the Petroleum Accountants Society of Canada 1988 Accounting Procedure, is intended to compensate the operator for the expenses relating to marketing a non-taking party's share of production. This view, however, ignores two important points. The first is that the overhead pertains to the operation of a well for the joint account, while the marketing of production, on the other hand, is not intended to be a joint operation. The second is the fact that the operator is not necessarily the party marketing a non-taking party's share of production. 
market the non-taking party's share of production, the competing objectives of operators and non-operators were considered and balanced. The operator requires the protection that it is never required to displace its share of production to accommodate a non-operator, and wishes to be compensated for the extra expenses it is forced to incur by marketing another party's share of production. A non-operator, on the other hand, must be protected from unreasonable long term contracts or non-arm's length arrangements.

\section{Operator's Options if a Party Does Not Take in Kind}

Insofar as a party did not take in kind, Clause 602 of the 1981 document provided that either its production could be sold at the same price that the taking party "receives for its own share of production" or the taking party "could purchase the same for its own account at the field price prevailing in the area." Given the deficiencies previously noted with that provision, Subclause 602(a) of the 1990 document was structured to provide the operator with the authority, ${ }^{18}$ as the agent of the non-taking party, to:

i) sell the non-taking party's production for the same price as the operator receives under the operator's own production sales contract with an arm's length third party;

ii) sell that production under another arm's length transaction for a market price; or

iii) purchase that production for its own account at a market price.

As a non-taking party should have the right to know the manner in which its share of production is being disposed, the taking party is required to advise the non-taking party of the option pursuant to which the production was disposed within one month of the commencement of that disposition.

The proceeds to be received by a non-taking party from the sales in (i) and (ii) shall be "less all direct processing and transportation expenses pertaining thereto and the applicable marketing fee prescribed by Clause 604." To minimize the likelihood that a taking party would use the third option to purchase the non-taking party's production for resale, that option does not permit the taking party either to net out processing and transportation expenses or to compensate itself with a marketing fee.'

\section{Fiduciary Obligations Re Paragraph 602(a)(iii)?}

Some commentators have expressed concern that a party which purchases a non-taking party's share of production for resale pursuant to paragraph 602(a)(iii) of the 1990

18.

Although the Subclause states that the operator does not have the obligation to market production on behalf of the non-taking party, one of the parties must market that production if the well is to be produced.

19.

Note that paragraph (a) (iii) does not enable the taking party to net out processing and transportation expenses against the proceeds to be provided to the non-taking party. This reflects the fact that the taking party would be purchasing the production at the first point of measurement under the option. It would have taken the future processing and transportation expenses associated with that production into account in its determination of the market price at which the production would be purchased. 
document could be liable to the non-taking party for breach of a fiduciary obligation in light of Midcon Oil \& Gas Limited v. New British Dominion Oil Company Limited, and Thomas L. Brook, ${ }^{20}$ and the Sorrel case, notwithstanding the fact that the taking party may have initially purchased the non-taking party's share of production for the "market price." 21

It is beyond the scope of this paper to review these cases and their possible application to the resale issue. When examining the issue, however, it is important to recall that the authors of the 1990 CAPL Operating Procedure had the opportunity to prohibit the resale possibility through a minor change to paragraph $602(\mathrm{a})(\mathrm{iii}) .^{22}$ As evidenced by the annotations, the document does not prohibit the resale of production by a taking party, largely because of the likelihood that the non-taking party had chosen not to market its own share of production during the applicable period. As long as the non-taking party receives the "market price," the paragraph does not even require the operator to disclose the manner in which it chose to handle the production subsequently, let alone account for profit.

Notwithstanding that observation, it is undoubtedly the better practice for a party which intends to purchase a non-taking party's production pursuant to paragraph 602(a)(iii) to review market conditions carefully and to document those findings in its records in order to justify its "market price." While the definition of market price places the onus on the non-taking party to demonstrate that a particular market price was unreasonable, a nontaking party probably would have less difficulty satisfying this onus in practice if the taking party were purchasing the non-taking party's production under paragraph 602(a)(iii), particularly if the taking party were selling that production for a profit or if the taking party were purchasing the production for its own use in circumstances in which there was not an established alternative market for that production.

\section{Contracting Restrictions Under Subclause 602(b)}

Clause 602 of the 1981 document had provided operators with the opportunity to market a non-taking party's share of production for "... such periods of time only as are consistent with the minimum needs of the industry under the circumstances but in no event shall any contract for the sale of the Joint-Operator's share of production be made for a period in excess of one (1) year."

[1958] S.C.R. 314 (S.C.C.) [hereinafter "Midcon"].

21. See for example. J. Jay Park, "Marketing Production from Joint Property: What Will Happen in the 1990s" and Edward Evans, "Fiduciary Duties in Oil and Gas Operations" in Oil \& Gas Operating Agreements (Edmonton: Legal Education Society of Alberta. 1991). Another recent case addressing the fiduciary relationship is Trilogy Resource Corp. v. Dome Petroleum Lid. (1990), 76 Alta. L.R. (2d) 140 (Alti. Q.B.).

22. This could have been addressed by providing that the operator could purchase the production for its own "consumption," instead of for its own "account." However, if this purchase of production were to enable an operator to sell production which it previously had been using in its producing operations, the amended provision would allow the operator to do indirectly the thing that the proposed amendment was designed to prohibit. 
It was apparent that the authority granted to the operator under the 1981 document was far too broad, however, as a non-operator might not even realize that it is not taking its share of production in kind. As a consequence, the principles in Subclause 602(b) of the 1990 form are far more restrictive. Purchases under paragraph 602(a)(iii) may not exceed one month, unless the applicable contract entered into by the operator with an affiliate is terminable at any time on notice of not greater than one month. If the operator proposes to sell production under paragraph 602(a)(i) or (ii) through contracts which either exceed one month or are not terminable at any time on notice of not greater than one month:

(i) the operator is required to notify the non-operator of the intended contract, together with a summary of the material terms;

(ii) the non-operator shall elect, within ten days of the receipt of that notice, whether it wishes its production sold under that contract; and

(iii) if the non-operator does not consent to the contract, it shall advise the operator whether it intends to take in kind or whether it wishes the operator to continue to market the production under the short term arrangements in Subclause (a).

Paragraph 602(b)(iii) enables the non-taking party to continue to require the operator to sell its production under short term arrangements if it is not prepared to consent to a contract. If that party believes that it can obtain a preferable contract in the next several months, it may be unwilling to accept the operator's proposed contract.

\section{Non-operator's Options if Operator Does Not Take in Kind}

Clause 603 of the 1981 document had addressed only the possibility that the operator was the non-taking party. Clause 603 of the 1990 document has been amended to address the additional possibility that the operator might choose only to take its own share of production in kind where at least one other party is not taking its share of production in kind. The provision was also amended to require the operator to provide the other parties with the information they require to exercise their rights under the Clause.

\section{THE MARKETING FEE (CLAUSE 604)}

As noted previously, a party which marketed a non-taking party's share of production pursuant to the 1981 form was not entitled to any compensation for its efforts in selling that production, a result which was widely perceived as being unfair to the taking party. Clause 604 of the 1990 document, on the other hand, enables the taking party to charge the non-taking party a marketing fee with respect to production being sold under the arm's length arrangements in paragraphs 602(a)(i) and (ii). This is one of the most contentious provisions of the 1990 document.

There are two alternates in the Clause. Alternate $\mathrm{A}$ is a flat fee of $2.5 \%$, and Alternate $B$ is a fee which is negotiated for each individual product. While Alternate A may be attractive for its simplicity. Alternate B enables the parties to tailor the fee to their particular fact situation. If production of liquids is expected under an agreement, it is likely that the parties would either use Alternate B or amend the percentage in Alternate A. 
The marketing fee is not based on the ultimate sale price. It is either based on the "value" of the product at the wellhead or a specified fee. Although easier to calculate than a wellhead based fee, it is important to remember that a fee based on the gross sale price could be significantly greater, depending on the ultimate point of sale and the degree to which the product had been enhanced. ${ }^{23}$

\section{THE MISCELLANEOUS MARKETING PROVISIONS (CLAUSES 605-608)}

Clause 605 of the 1990 document (Clause 604 of the 1981 form) has been amended. A party marketing another party's share of production pursuant to Article VI may pay the royalties attributable thereto directly to the lessor, in which event those royalties would be deducted from the amount remitted to the non-taking party.

Clause 606 of the 1990 document (Clause 605 of the 1981 form) has been expanded significantly. The disposing party shall pay the non-taking party its share of net proceeds within ten days of its receipt. If it fails to do so, the provisions of Subclause 505(b) shall apply, mutatis mutandis, such that the non-taking party would be able to charge interest and have access to the other default remedies. Since the direct processing and transportation costs may not be known at the time of the distribution of proceeds, the disposing party may invoice the non-taking party for those costs after the fact. In that event, the disposing party would also have access to the remedies in Subclause 505(b) to secure payment of those expenses.

Clause 607 and 608 are new provisions. Clause 607 provides a non-taking party with the right to audit the disposing party's records with respect to sales under Article VI. However, the disposing party shall not be required to provide auditors with any access to any contract described in paragraph 602(a)(i), as those contracts contain proprietary information which a party is not required to disclose to auditors. Clause 608 is a general indemnification provision whereby the non-taking party indemnifies the taking party with respect to any losses the taking party may suffer by virtue of defects in the non-taking party's title to production. A party selling production is often required to provide a title warranty with respect to production being sold by it. As it is not feasible for a disposing party and a non-taking party to enter into a side agreement in each instance, this general indemnification provision has been included.

\section{INDEPENDENT OPERATIONS}

The 1990 document continues to address the independent operations mechanism in Articles IX and X. Given the complexity of the topic, though, this examination will be divided into four major components: the casing point election, the mechanics of conducting an Article $\mathrm{X}$ independent operation, the penalties applicable thereto and the general provisions of Article $\mathrm{X}$.

23. The value of the substance at the wellhead is determined by subtracting from the sale price all of the costs and expenses associated with product enhancement, such as transportation and processing costs. In this respect, it is similar to the royalty calculation provisions under a freehold oil and gas lease. 


\section{A. CASING POINT ELECTION}

While conceptually similar to the comparable 1981 provision, Article IX of the 1990 document has been revised significantly to reflect more accurately the manner in which operations are conducted in practice. The major changes to the Article are as outlined below.

\section{Submission of Completion Program}

Clause 901 of the 1981 form stated clearly that the approval of the original AFE did not constitute a party's approval of the completion program set forth in that AFE. However, Clause 902 of that form did not require the operator to issue a revised completion program to the parties. Subclause 902(a) of the 1990 document, on the other hand, recognizes that the testing program described in the initial AFE is actually only a predicted testing program in the event that certain assumptions are accurate. The operator is required to advise the non-operators of its proposed completion program in the context of its review of the data from the well.

\section{Objections to Completion Program}

Clause 902 of the 1981 form did not contemplate the possibility that the non-operators would object to the operator's proposed completion program. While, in part, this may have reflected the view that the operator best understood the property, it more likely reflected the philosophy that the parties would negotiate a suitable resolution if it were to become an issue in practice. Subclause 902(b) of the 1990 document, however, contemplates the possibility that there may be objections to the operator's proposed program. It provides that a party which elects to participate in the completion attempt shall be deemed to have approved the operator's proposed program unless it otherwise advises the parties in the election period. If the operator were to propose the material alteration of its program as the result of such an objection, all of the parties could re-elect whether to participate in the operation, as the operation would differ materially from that to which the original election pertained. ${ }^{24}$

\section{Percentage of Participation in Operation}

Clause 1015 of the 1981 form applied to the casing point election of the parties, such that a party could elect to participate in the operation for only its working interest or for its proportionate share of all available interests. Subclause 1002(c) of the 1990 document provides the participating parties with far greater flexibility, as will be considered in more detail later. 


\section{Scope of Election}

Clause 902 of the 1981 form did not entitle a party to elect to participate in only the setting of production casing. It was required either to participate in the completion of the well or to elect not to participate in the operation. Subclause 902(b) of the 1990 document provides more flexibility. A party may limit its election to participation in the setting of production casing and the suspension of the well. If one or more of the other parties were to proceed to conduct the completion attempt at that time, a penalty prescribed by Alternate $903 \mathrm{~A}$ with respect to that party would be based only on that portion of the costs not assumed by it.

\section{Limitation on the Program}

Clause 902 of the 1981 form had only contemplated a full completion program, but Subclause 902(d) of the 1990 document is again more flexible. The operator's proposed program may be the setting of production casing and the suspension of the well, so that the well may be re-entered at some later date for the conduct of an unspecified completion program. Approval of that program by the parties, however, does not empower the operator to re-enter the well at a later date to attempt to complete the well for the account of those parties without obtaining additional approvals pursuant to Clause 1008 .

\section{Penalty}

A major change has been made to Alternate $A$ of the 1990 document. The magnitude of the production penalty under Alternate $A$ in the 1990 document depends on the classification of the applicable zones as pertaining to a development well or an exploratory well. The 1981 form, on the other hand, tied the penalty to the development well penalty, a result which was inconsistent with Clause 1008 of that form.

\section{B. THE MECHANICS OF CONDUCTING AN ARTICLE X INDEPENDENT OPERATION}

This portion of the paper will briefly examine such matters as the issuance of the operation notice, the reply to the operation notice, limitations on the issuance of the operation notice, the time for commencing the operation, the operator for the operation, the separate election where the well status is divided and the nature of the earning obligation.

\section{The Issuance of the Operation Notice}

The scope of Clause 1002 of the provision has been expanded to include the construction and installation of production facilities, as defined in Subclause 101(z).

\section{The Reply to the Operation Notice}

Subclauses 1002(b), (c) and (d) of the 1990 document include several significant revisions to the comparable provisions of the 1981 form. 
The special 48 hour election mechanism applicable to a deepening or recompletion had been included in Subclause 1008(c) of the 1981 form. This provision has been clarified and moved to Subclause 1002(b) in the 1990 document, so that all of the response periods are included in Subclause 1002.

Of more importance is the determination of participating interests pursuant to Subclauses 1002(c) and (d) of the 1990 document. Clause 1015 of the 1981 form had provided that a party which elected to participate in an operation could elect to participate either for its working interest or for its proportionate share of all available interests. Subclause 1002(c) of the 1990 document, on the other hand, enables a party to elect to participate for its working interest, for its proportionate share of all available interests or for its proportionate share of all available interests, with a limit on the maximum percentage of participating interest. Failure of a proposing party in its operation notice, or a receiving party in its response thereto, to limit its participation in the operation shall be deemed to have been an election to participate for its proportionate share of all available interests, such that all parties are required to disclose their positions to the other parties. If even one party elects to assume its proportionate share of available costs, the interests will be fully subscribed. If there is an unassumed percentage of participation after the process, the participating parties shall attempt to allocate the unassumed interest within a prescribed time or the notice shall be void. Once the status of the operation and the positions of the parties have been determined, the proposing party shall promptly give notice to the parties specifying the manner in which the costs, risks and benefits of the operation shall be shared because of the revised Clause 1016. Otherwise, the nonparticipating parties would not know the parties which are receiving the penalty and the allocation of the penalty among them.

\section{Limitations on the Issuance of the Operation Notice}

The only material change to the 1981 provision comparable to Subclause 1002(a) of the 1990 document was the reduction in distance between the related well and the proposed well from three miles to two miles (3.2 kilometres).

\section{The Time for Commencing the Operation}

Clause 1003 of the 1981 form has been revised significantly in the 1990 document, mostly through a clarification of the provision. There were two material conceptual changes, however. The first was the inclusion of a statement that a receiving party would not be entitled to any information respecting an operation until such time as it becomes a participating party in the operation. The second was the extension of the period during which an operation could be conducted pursuant to an operation notice. Clause 1003 of the 1981 form had required the operation to be commenced within sixty days of the receipt of the operation notice. Clause 1003 of the 1990 document, on the other hand, extends that period to ninety days following receipt of the operation notice, with a special one hundred and fifty day commencement period respecting a production facility, given the logistical difficulties associated with the construction or installation of a production facility. 


\section{The Operator for the Operation}

Clause 1004 of the 1981 form stated that the operator would conduct the operation if it elected to participate in the operation. However, it ignored two important facts. The operator may have planned to allocate its personnel to other projects. Moreover, the operator may not have been able to conduct the operation under the timing and cost constraints proposed in the notice.

To ensure that a proposing party remains accountable with respect to operations it proposes, Clause 1004 of the 1990 document has been structured so that the proposing party would conduct the operation unless either the parties otherwise agree or that party would be disqualified by Subclause 202(a). If the operator were a participating party, but not the proposing party, it would succeed the proposing party as operator upon the completion of the operation or that particular phase thereof as the proposing party and the operator may agree.

The non-operators may not wish the operator to conduct the operation if they had confidence that the proposing party could conduct the operation properly for the cost set forth in the AFE and they doubted that the operator could conduct the operation for the same cost. That being the case, the provision was not structured to provide the operator with the option to conduct the operation. There will likely be instances in which the operator would probably conduct the operation, though. If there were safety or other technical concerns respecting the proposing party's ability to conduct the operation, the other parties presumably would attempt to negotiate an alternative arrangement. Similarly, if the rig is on location, the operation is the setting of casing or the deepening of a well and the operator is not prepared to participate, it is probable that the participants would wish the operator to conduct the operation on their behalf because of the desire for technical continuity and the difficulty in transferring contracts. However, this mechanism was not included in the document because of the need to address the issue in the context of a particular fact situation.

An operator which is concerned that it may lose operatorship for a joint drilling operation should issue a drilling AFE in conjunction with an operation notice, rather than in accordance with Article VII. Otherwise, a non-operator could frustrate the operator by refusing to approve the AFE and immediately issuing its own operation notice for the well.

\section{The Separate Election Where the Well Status is Divided}

Although the underlying principles are quite similar, Clause 1005 of the 1981 form has been entirely redrafted, mostly to clarify the application of paragraph 1005(b)(iii) of the 1981 form.

\section{The Nature of the Earning Obligation}

As noted previously in the consideration of the definition of Authority for Expenditure, the Passburg case considered the degree to which an operator could deviate materially 
from an approved AFE. The court held that the operation described in an AFE is a condition of the approval, such that an operator does not have the discretion to alter the scope of the operation materially.

To what degree, therefore, can the participating parties intentionally deviate from the terms of the operation notice and still earn the penalty presented in Article X? Given that an operation may differ from that described in an operation notice in costs, timing, location and depth, and that the differences may be material or of little consequence, the answer would seem to depend on the type and degree of the deviation. As a general rule, immaterial differences in timing or cost probably would not appear to affect the penalty because of their dependency on external factors. Similarly, a material difference in costs would probably not affect the penalty if the original cost estimate had been reasonable in the circumstances and the participating parties had no reason to revise the estimate prior to the commencement of the operation. Where, on the other hand, the participating parties have (or should have) knowledge of developments which would materially alter the costs or timing of the independent operation, the validity of the operation notice would seem to be jeopardized if those changes might have influenced the non-participating parties to elect to participate in that operation. Similar considerations would apply to such technical factors as location and depth.

If an operation were, in essence, a different operation from that proposed, there is arguably a duty on the participating parties following the Passburg case to advise the nonparticipating parties of such a change promptly and to allow them the opportunity to reelect to participate in the operation, even if it has already been commenced. While it was not practicable to structure the document to address this principle in any detail, the 1990 document addresses the issue indirectly. Clause 1007, for example, ties references to "such well" to "an independent operation proposed in an operation notice."

\section{PENALTIES UNDER ARTICLE X}

The principal penalty provisions in the 1981 form had been Clause 1007 (drilling of development and exploratory wells), Clause 1008 (deepenings, recompletions, etc.) and Clause 1010 (wells to preserve title). While the 1990 document includes comparable provisions, they have been significantly revised, and the 1990 document also includes Clauses 1021 and 1022 respecting the installation and expansion of production facilities.

\section{Clause 1007 Penalties}

Clause 1007 is comprised of three major components: the penalty in Subclause 1007(a), the encumbrance qualification in Subclause 1007(b) and the miscellaneous mechanical provisions in Subclauses 1007(c), (d) and (e).

(a) Subclause 1007 (a): Four significant changes have been made to Subclause 1007(a) in the 1990 document. 
The first is that Subclauses 1007(a) and (b) of the 1981 form have been combined for simplicity, with paragraph (a)(iv) including a special feature addressing the situation in which Clause 1005 applies.

The second is that production proceeds are calculated at the wellhead, such that product enhancement costs are first deducted. The participating parties arguably have no authority to charge processing and transportation costs against the penalty account under the 1974 and 1981 CAPL Operating Procedures. Given that the deduction mechanism in the 1990 document has some inherent ambiguity, the manner in which this authority is applied should be monitored closely to minimize the likelihood of abuse.

The third is that only charges which have, in fact, been paid can be charged under paragraph 1007(a)(i). This clarifies the intention of the 1981 document that "phantom" royalties which otherwise would have been paid during a royaltyfree period cannot be charged to the penalty account.

The fourth is that a $200 \%$ penalty on equipping costs has been included in paragraph 1007(a)(iii). This replaces the interest adjustment in the comparable provision of the 1981 form, largely because of the burden the interest adjustment placed on accounting personnel.

(b) Subclause 1007(b): The starting point in an examination of Subclause 1007(b) is an examination of Clauses 801 and 802 .

Clause 801 states that a party which has an encumbered interest shall free the interest from that burden when the interest is surrendered, forfeited or subject to a production penalty. If it fails to free the interest from that burden, it shall indemnify the parties for any resultant losses they may suffer. The only way that it can free the interest from the burden is to structure the contract creating the encumbrance in a manner which enables it to do this. It is imperative, therefore, that a company which encumbers its interest attempts to structure its arrangement so that it would not have an adverse impact on its co-venturers if they were subsequently to acquire the interest through the application of the surrender or penalty provisions of the document.

Some encumbrances will warrant special treatment under the Operating Procedure, however, and will be exceptions to the general principle in Clause 801. As noted in Clause 802, these will either be created pursuant to the agreement or recognized expressly in the agreement as being existing burdens which will have a special status under the Operating Procedure. The purpose of Clause 802 is not to encourage the creation or recognition of encumbrances, however. It is to distinguish between encumbrances which the parties believe warrant special treatment under the Operating Procedure and those which they believe do not. Encumbrances which are not created in the agreement only fall within the scope of Clause 802 if the parties voluntarily agree to provide them with the special status in the agreement. 
If a participating party's interest is subject to an encumbrance which falls within the Clause 802 exception, payments made by that party are ignored for the purposes of Subclause 1007(a). If a non-participating party's interest is subject to such an encumbrance, however, payments pertaining to the encumbrance shall be made on behalf of that party by the applicable participating parties, and $150 \%$ of such amounts shall be included in paragraph 1007(a)(i) as between only the applicable participating parties and that non-participating party. The additional amount is designed to compensate the participating parties for the delay of penalty payout caused as a result of the payment of such amount.

(c) Miscellaneous mechanical provisions: Subclauses 1007(d) and (e) of the 1990 document have been revised to clarify the intention of the comparable provisions of the 1981 document.

\title{
2. Clause 1008 Penalties
}

Two material changes have been made to Clause 1008. The first is that the scope of the Clause has been expanded to include the re-entry and completion of a suspended well, as a result of the changes to Article IX. The second is that payments made to a nonparticipating party pursuant to Subclause 1008(d) of the 1990 document are to be treated as operating costs for the purposes of paragraph 1007(a), rather than as completion costs, as was the case in the comparable provision of the 1981 form.

\section{Clause 1010 Penalty}

Clause 1010 has been entirely rewritten in an attempt to rectify major conceptual deficiencies in the 1981 Clause, which stated:

\begin{abstract}
Notwithstanding Clause 1007, if the operation is the drilling of a well required to preserve title, the drilling of which is commenced during the final one-sixth $(1 / 6 \mathrm{th})$ or the final three hundred sixty five (365) days, whichever is the shorter period, of the term of a title document which is due to terminate as to all or part of the lands or formations contained therein unless a well similar to the proposed well is sooner drilled on the joint lands, (which terminating lands and formations and expected preserved lands and formations shall be described in the operation notice) the non-participating parties shall, effective upon the well reaching sufficient depth to prevent such termination, assign to the participating partics (proportionate to the participating parties' participation in the operation) all the non-participating partics' interest in and under the title documents insofar as they relate to the lands or formations with respect to which such termination would have occurred had the well not been drilled. unless the non-participating parties have prior to the date upon which such termination would have occurred, drilled (or are in course of drilling) another well which also has prevented or will prevent such termination. The non-participating parties' rights with respect to access to the wellsite and information with respect to a well subject to this Clause shall be as provided in Clause 1018 .
\end{abstract}

The major conceptual changes to the Clause in the 1990 document are as follows.

(a) Scope: The 1981 provision applied only to the drilling of a well. While the 1990 provision only addresses wells which preserve title, it has been expanded 
to apply not only to the drilling of new wells, but also to the completion and recompletion of existing wells. However, the 1990 provision was not expanded to address the possibility that other work could enable some of the parties to satisfy the work requirements necessary to maintain portions of permit lands in good standing, as is possible in British Columbia and Saskatchewan. ${ }^{25}$

(b) Timing: The 1981 provision applied if a well was drilled during the shorter of the final one-sixth or 365 days of the term of the title document. This was generally regarded as too inflexible. While that period may have been appropriate for some special areas with limited access, it was usually perceived as being too long. The 1990 provision has been modified to include more flexibility. Paragraph 1010(a)(iv) enables the parties to tailor the time period to their particular fact situation, having regard to such factors as surface accessibility and required regulatory approvals in environmentally sensitive areas.

(c) Preserved lands: The interest to be forfeited to the participating parties under the 1981 provision comprised the lands or zones which would have terminated under the applicable title document had the title preserving well not been drilled. The term "preserved lands," however, was not defined, such that Clause 1010 of the 1981 form was structured somewhat awkwardly.

A definition of "preserved lands" was included as paragraph 1010(a)(ii) in the 1990 document to attempt to minimize this confusion, and that definition is as follows:

\footnotetext{
"preserved lands" means any joint lands which would have been forfeited pursuant to a particular title document had a title preserving well not been drilled, completed or recompleted at the time and in the manner prescribed herein, subject to the designation of preserved lands pursuant to Subclause $309(\mathrm{~d}) .^{26}$
}

(d) Similar well mechanism: The 1981 provision enabled a non-participating party to participate in another well which would have prevented the termination to avoid the forfeiture of its interest, such that it would be subject only to the 1007 penalty respecting the initial well. This mechanism posed two major problems. Firstly, the participating parties in the initial well under the 1981 provision did not know the type of penalty applicable to the initial well until the opportunity to drill a similar well had expired. Secondly, the 1981 provision did not protect the participating parties in the initial well against the possibility that the nonparticipants would drill a lower risk second well after assessing the success of the initial well, especially given the fact that a non-participant could drill a simple offset to a discovery well after scouting that well. of an additional special title preserving mechanism in the main agreement.

26. Subclause 309(d) enables a party to require an early lease designation for the purposes of Clause 1010 where leases cannot be selected for all of the lands included in the title document, as discussed previously. 
Both of these concerns were addressed in Subclauses 1010(b) and (c) of the 1990 document. Subject to the qualifications in Subclauses 1010(c) and (d), Subclause 1010 (b) provides that a non-participating party with respect to a title preserving well shall forfeit:

$100 \%$ of its working interest in the well and its spacing unit at the completion of the operation, insofar only as the well and rights pertain to the preserved lands; and

$100 \%$ of its remaining working interest in the balance of the preserved lands at the date they otherwise would have reverted to the grantor of the applicable title document.

If certain shallow rights were not included in the preserved lands, the production penalty prescribed by 903,1007 or 1008 would apply to the well and its spacing unit as regards those zones.

Subclause 1010(c) applies in the unlikely event that a "subsequent title preserving well" is drilled, and addresses three possible cases.

The first is the situation in which a non-participating party with respect to the title preserving well participates in the subsequent title preserving well. It will not be required to forfeit its working interest in any common preserved lands pursuant to paragraph (b)(ii). (It could still forfeit an interest, though, in the spacing unit for the title preserving well pursuant to paragraph (b)(i).)

The second is the situation in which a non-participating party with respect to the subsequent title preserving well was also a non-participating party with respect to the title preserving well. It generally shall forfeit its working interest in the spacing unit of the subsequent title preserving well to the participating parties therein, rather than to the participating parties in the title preserving well. ${ }^{27}$ Either paragraph (b)(ii) or Subclause (d) would apply to its remaining interest in the balance of the lands preserved by the title preserving well.

The third is the situation in which a non-participating party in the subsequent title preserving well was a participating party in the title preserving well. It would generally only be subject to a production penalty respecting the subsequent title preserving well. However, it would be subject to the forfeiture in paragraph (b)(ii) if the well preserved lands in addition to those preserved by the initial title preserving well, since a subsequent title preserving well can also be a title preserving well with respect to another portion of the joint lands.

(e) Allocation of penalty: The interest to be forfeited by a non-participating party pursuant to Clause 1010 of the 1981 form was to be assigned "... to the 
participating parties (proportionate to the participating parties' participation in the operation) ...." This statement was incorrect. It literally stated that a party which participated for only its own working interest share of the cost of the well would receive a portion of the forfeited interest without having incurred even $1 \phi$ of the share of costs applicable to the interest of the non-participating party. ${ }^{28}$ This result was corrected through the revision to Clause 1016.

Subclause 1010(d) of the 1990 document also addresses the allocation of the penalty if there are common preserved lands. Paragraphs 1010 (b)(i), (c)(i) and (c)(ii) include special rules which are applicable to the spacing units for the title preserving well and the subsequent title preserving well. The forfeited interest in the remainder of the common preserved lands is allocated equally to the title preserving well and the subsequent title preserving well. That interest is then apportioned among the participants in the respective wells pursuant to Clause 1016.

\section{Clauses 1021 and 1022}

Clauses 1021 and 1022 pertain to the construction, installation and expansion of "production facilities," a topic which was not addressed in the 1981 document. If the construction of a minor production facility were proposed under the 1981 form, there would be a problem if less than all of the parties were prepared to participate in the construction of that production facility. From the perspective of the participants, there would be concerns respecting a timely response to the proposal of the operation and the degree to which the facility would be utilized if built. From the perspective of the nonoperators, they would face the option of either taking their production to some other facility or negotiating a processing or transportation agreement with the facility owners if sufficient capacity in the facility were available.

Clause 1021 is an attempt to balance two competing objectives; the most effective exploitation of the resource and the right of ownership to exploit the resource. The fundamental principle in Clause 1021 is that the construction of a production facility should be permitted, provided that no party would be required to participate in the facility, either directly, by paying its share of the cost in cash, or indirectly, through a cost recovery mechanism. If served with an operation notice for the construction or installation of a production facility, a receiving party may:

(i) participate in the operation;

(ii) elect not to participate in the operation, but to take its share of production in kind before the inlet of the production facility;

(iii) elect not to participate in the operation and to incur a $200 \%$ penalty in a manner analogous to Clause 1007; or

(iv) attempt to negotiate a user fee outside the document.

2x. This provision would be unlikely to pose a problem in practice if the parties were aware of the deficiency. A participating party which assumed penalty expenses could suffer a loss, though, if applicable personnel were not aware of the flaw and mechanically applied the provision. 
Clause 1022 basically applies the principles in Clause 1021 to the expansion of an existing production facility, subject to Clause 1408. The provision is quite different from the provision traditionally found in a $\mathrm{CO} \& \mathrm{O}$ agreement, though. A party which receives an operation notice respecting the expansion of a production facility only has the option to participate in the expansion or to incur the prescribed penalty. A CO\&O agreement, on the other hand, does not force a non-participating owner to participate in an expansion or to pay for it indirectly through a penalty recovery.

\section{THE GENERAL PROVISIONS OF ARTICLE $X$}

Significant changes to the remaining provisions of Article $\mathrm{X}$ are as outlined below.

(a) Clause 1011: The types and formats of the data supplied to a non-participating party shall correspond to industry data sales practices.

(b) Clause 1012: Two notable changes have been made to the Clause. The first is that the right of the participating parties to utilize facilities has been limited to "production facilities." The second is that the capital fee used in the 1981 form has been deleted.

(c) Clause 1013: Subclause 1013(b) has been added to encourage operators to comply with the obligation to issue a periodic payout statement. If the costs prescribed by the applicable production penalty provision (Clause 903, 1007, 1008,1021 , or 1022) have been recovered and notice of that recovery either has not been issued to the non-participating parties or has been issued later than it should have been, a non-participating party is entitled to interest on the funds which should have accrued to it.

(d) Clause 1016: Clause 1016 of the 1981 form had stated:

Any assignment or forfeiture of any interest in the joint lands as herein provided shall be made to the applicable assignees in the proportions that their respective participating interests bear one to the other, unless the contrary is expressly otherwise provided herein.

There was a fundamental flaw in that provision if a party limited its participation to its working interest. A penalty should have accrued to the participating parties in the proportions in which they assumed the share of the costs of a nonparticipating party, not in the proportion of the participating parties' participation in the operation, a deficiency which has been corrected in Clause 1016 of the 1990 document.

(e) Clause 1017: The 1981 provision has been entirely rewritten, largely because it did not address both liability and indemnification.

(f) Clause 1019: The distance between the existing well and the proposed well has been reduced in the 1990 document to two miles (3.2 kilometres) from three miles. 
(g) Clause 1020: The 1981 provision had provided the proposing party with an unqualified authority to enter into a unit agreement. Since the participating parties could also be negotiating tract factors or pooled interests with respect to other lands in which they have an interest, they may only unitize or pool a well subject to a production penalty in the 1990 document with the consent of the non-participating parties, which consent may not be unreasonably withheld.

\section{OPERATION OF PRODUCTION FACILITIES}

As noted previously, the scope of the 1990 document has been expanded significantly by including provisions enabling one or more of the parties to construct, expand and operate a limited class of minor facilities. While parties should continue to prepare comprehensive $\mathrm{CO} \& \mathrm{O}$ agreements for significant production facilities, the nature of many minor facilities is such that it is not feasible to prepare an individual agreement for each of those facilities.

Article XIV, therefore, has been structured to address the fundamental issues associated with the construction, ownership and operation of minor facilities in accordance with generally accepted industry principles applicable to that class of facilities. However, the Article does not address those matters in the detail in which they would traditionally be handled in a CO\&O agreement, and the Article also ignores many other issues which are normally included in a comprehensive facility agreement.

While a detailed review of the principles in Article XIV of the 1990 document is beyond the scope of this paper, some of the topics addressed in the Article are: the ownership of production facilities; a commitment to deliver production; the use of production facilities; third party custom usage; the allocation of costs and products; the allocation of losses and shrinkage; the expansion of production facilities to handle substances produced from other lands; and a dispute resolution mechanism. ${ }^{29}$

\section{DISPOSITION OF INTERESTS}

While Clause 2401 of the 1981 and 1990 documents are similar in approach, there have been a number of major changes to the Clause, as follows:

(a) Nature of disposition: The introductory portion of Clause 2401 has been revised in the 1990 document, to broaden the references to disposition throughout the Article. The 1981 form had contemplated that assignments and sales were somehow distinct from "dispositions;"

(b) Response period to consent request: The 1981 form did not include any provision whereby the consent of another party was deemed to have been 
obtained if it failed to respond to a consent request within a specified period. The 1990 document, on the other hand, provides that failure of a party to object to a disposition within twenty days of the receipt of the consent request shall be deemed to be the consent of that party to the disposition;

(c) Grounds for withholding consent: Alternate 2401A of the 1981 form did not address the grounds upon which it would be reasonable for a party to withhold its consent to a disposition. Alternate 2401 A of the 1990 document was expanded to address the grounds upon which it would be reasonable for a party to withhold its consent, by stating that it could do so:

... if it reasonably believes that the disposition would be likely to have a material adverse effect on it, its working interest or operations to be conducted hereunder, including, without limiting the generality of all or any part of the foregoing, a reasonable belief that the proposed assignee does not have the financial capability to meet prospective obligations arising out of this Operating Procedure.

The addition arguably codifies, for the benefit of non-legal personnel, the common law respecting the reasonable grounds for withholding consent;

(d) Information to be included in Alternate 2401A \& B notices: The 1990 document requires the disposing party to include more specific information in a notice issued under Clause 2401 than was required in the 1981 form;

(e) Arbitration mechanism: The arbitration mechanism in Alternate 2401B of the 1981 form has been altered to minimize the possibility that either a disposing party or a receiving party would be motivated to attempt to abuse the mechanism. The first material change is that a reference to arbitration will operate to suspend the election period. The second is that the arbitrated value shall be the sale price for the interest, whether it is higher or lower than the estimate in the disposition notice; ${ }^{30}$

(f) Election period: The basic election period in Alternate 2401B of the 1990 document has been extended to thirty days from twenty days, subject to a special qualification if the disposing party's estimate had been referred to arbitration;

(g) Closing period: The period within which the disposing party is required to complete its transaction has been extended to within one hundred and fifty days of the issuance of the notice in the 1990 document. The corresponding period in the 1981 document had been within sixty days of the expiry of the notice period; and 
(h) Inclusion of consent mechanism in Alternate 2401B: Alternate 2401B of the 1981 document only enabled the offerees to prevent the completion of a disposing party's disposition to an unacceptable third party by exercising their first right of refusal. The 1990 document, on the other hand, also includes a consent mechanism analogous to Alternate 2401A. This ensures that an offeree would never be forced to pay more than it believes a property is worth solely in order to avoid an unsuitable partner it could have refused had the lower standard in Alternate $\mathrm{A}$ been chosen.

Clause 2402 of the 1990 document is quite similar to the 1981 provision, except that the "substantially all" reference has been clarified to correspond to the commonly accepted legal view that ninety percent comprises "substantially all." ${ }^{31}$

One of the more contentious provisions in the 1990 document is Clause 2404. It is comprised of two alternates. Alternate A reflects the traditional manner of effecting novations, and Alternate B provides that a novation may be deemed to be effected through the execution of less than all of the third parties if certain conditions are satisfied.

One of the consequences of the large number of corporate reorganizations and industry rationalization programs has been a multitude of novation agreements which have not been executed by the applicable third parties. Alternate B enables the assignor and assignee to effect a novation more simply where the assignor had complied with its other obligations under Clause 2401, if any. The difference from Alternate $A$ is that the third parties shall be deemed to have executed the novation agreement provided to them by the assignor, unless, within ninety days of its receipt, at least one of the third parties advises the parties that it is not prepared to execute that agreement and the reasonable objections it has to that agreement. (In practice, these objections would generally tend to be with respect to the identification of the parties or the description of the agreement or lands.)

The Alternate reflects the view that the benefit of effecting transactions in a timely manner outweighs any uncertainty caused by not having all of the parties execute the novation agreement, something which has not been of particular concern in unit and other production agreements. This view is premised on the determination that the primary reason for the backlog in the processing of novation agreements by other parties is attributable to the novations being assigned a low priority, not a multitude of objections to the documents.

The deeming mechanism places some minor, but critical, additional administrative duties on the parties. The assignor is required to provide the parties with a notice respecting the status of the processing of the agreement. Upon receipt of that notice, the other parties should ensure that a copy of the notice is placed with that agreement in its

3. While the reference to net hectares rather than value may initially seem dubious, it reflects the practical fact that a third party would seldom be in a position to question an allocation of the value among all of the lands in the transaction. The net hectares test, on the other hand, is relatively simple. 
records if the deeming mechanism applies to a party's execution, so that the risk of personnel subsequently missing the notice during a title review is minimized.

There is a duty on the part of an objecting party to advise the parties of its reasonable objections to the document at the time it gives its notice to the assignor. There are no guidelines as to what would be considered to be a reasonable objection, so it would usually be the subject of negotiation if the objection were something more substantive than "not having the opportunity to review the document" within the ninety day period.

This Alternate is unlikely to be widely accepted with respect to any property of significant value, but may ultimately prove to be attractive for minor value properties in light of industry efforts to streamline documentation. However, it will have largely accomplished its objective if its mere presence as an Alternate motivates parties to process novation agreements in a more timely manner than has recently been the case.

The Alternates and Subclauses 2404(a) and (b) refer to the major components of novation agreements, which are the assumption of obligations by the assignee with respect to the assigned interest, the effective date of the assignment (Subclause (a)) and the trust arrangement on which the other parties may rely until the agreement becomes effective pursuant to Clause 2404 (Subclause (b)). That agreement would also include other provisions, such as the responsibility for obligations accruing prior to the effective date of the assignment and any discharge of the assignor.

\section{MISCELLANEOUS PROVISIONS}

Notable changes which have been made to the remaining provisions of the document are outlined below.

(a) Clause 1104: Clause 1104 has been revised to reflect increased concerns respecting orphan wells and environmental liabilities, to minimize the possibility that a party would attempt to use the surrender mechanism to avoid its responsibility for abandonment costs. Subclause 1104(a) requires the retaining parties to pay to the surrendering parties the latter's share of the estimated net salvage value of the material and equipment on the surrendered lands, less their share of the abandonment costs applicable to the wells being assigned. Subclause 1104(b) states that a surrendering party is not released from obligations which had accrued prior to the surrender (including environmental liabilities) and its obligation to maintain information confidential. However, this obligation shall not extend to the obligation to abandon any well on the lands so assigned, since the estimated abandonment cost (including reclamation costs associated therewith) would be taken into account under Subclause 1104(a) at the time the accounts of the parties were adjusted.

(b) Article XVI: Two major changes have been made to Article XVI in the 1990 document. The first is that the scope of the force majeure definition does not include events which a party could have prevented with the exercise of reasonable diligence at a reasonable cost. The second is that a force majeure 
suspends the performance of the affected obligations not only for the period that the force majeure prevents the performance of the obligation, but also for such additional time as the affected party may reasonably require to commence to fulfil the obligation.

(c) Clause 1701: The Article in the 1981 form pertaining to cash and acreage contributions has been replaced by a provision respecting incentives. It states that incentives which accrue collectively with respect to the operation are shared by the applicable participants in the proportions of their participating interests. Incentives which accrue to the participants on the basis of individual criteria, on the other hand, are not shared under Clause 1701.

(d) Article XVIII: Article XVIII has been expanded to reflect more closely the manner in which oil and gas companies actually conduct their business. It addresses such matters as: i) the right of a party to use information for its sole benefit; ii) the application of the regulations and securities laws; iii) releases to permitted assignees; iv) releases to the technical, financial or other professional consultants of a party; $v$ ) releases to recognized industry associations; vi) releases to third parties for consideration; and vii) the continuation of confidentiality obligations.

(e) Clause 2001: Clause 2001 has been expanded to address both actual and anticipated breaches.

(f) Clause 2201: Clause 2201 includes a limited right to serve notice by telephone if the applicable prescribed notice period in the document is forty-eight hours or less.

(g) Clause 2901: A proviso has been added at the end of Clause 2901 which states that the provisions relating to audit, liability, disposal and salvage of material and enforcement on default continue for six years after the date upon which the Operating Procedure would otherwise terminate. This proviso is particularly relevant with respect to liabilities which were only contingent at the date of termination, especially in light of the increased sensitivity to environmental issues.

\section{CONCLUSION}

The Canadian Association of Petroleum Landmen has attempted to address the existing and anticipated needs of the oil and gas industry in the 1990 CAPL Operating Procedure. The degree to which this attempt has been successful will be revealed over time, as users assess the practical impact of the revisions on their operations. Although one can only speculate about the manner in which users will perceive that the 1990 document satisfies those needs, it is clear that revisions to the 1990 document will be required in due course, to reflect both deficiencies in the document which will have since become apparent and the new needs of the ever-changing oil and gas industry. The Canadian Association of Petroleum Landmen will then once again, in consultation with interested members of the 
oil and gas community, prepare a new version of the CAPL Operating Procedure to address those needs, as the custodian of what is, in effect, a living industry document. 